\title{
O COMPORTAMENTO DE ESCOLHA POR UM CURSO SUPERIOR NO SISU: UMA ABORDAGEM DA TEORIA DA ESCOLHA RACIONAL
}

\author{
CAMPOS, Isabella Araújo ${ }^{1}$ \\ MENDES, Wesley de Almeida
}

RESUMO: Este ensaio teórico buscou discutir, à luz da teoria da escolha racional, qual seria a lógica da escolha do estudante por um curso superior após a adesão do ENEM/SiSU nas Instituições de Ensino Superior brasileiras. Apresenta-se como proposição, que os candidatos que participam do SiSU, agem de modo racional, visando os seus próprios interesses na escolha do curso no qual desejam ingressar. A teoria da escolha racional, portanto, considera que o indivíduo, dotado de racionalidade, faz suas escolhas de modo a alcançar o seu próprio objetivo e ter ganhos pessoais, com base nos recursos e informações que dispõe. Decorrendo desta reflexão, acredita-se que muitos dos indivíduos que se inscrevem no SiSU para tentar pleitear uma vaga no sistema superior de ensino, fazem a escolha do curso baseado no que é possível em detrimento do que é desejado. Portanto, esse novo sistema pode estar banalizando a escolha do curso superior. A sugestão que emerge é que sejam direcionados esforços para reflexões e estudos sobre a influência do SiSU no comportamento do estudante na escolha do curso. Além disso, sugere-se também a importância em se considerar os aspectos culturais e não racionais dos indivíduos que se inscrevem no SiSU.

Palavras-Chave: Teoria da Escolha Racional. ENEM/SiSU. Escolha do Curso Superior.

SUMMARY: This theoretical essay sought to discuss, in the light of rational choice theory, what would be the logic of the student's choice for a higher education course after ENEM / SiSU membership in the Brazilian Federal Institutions of Higher Education. It is presented as a proposition, that candidates who participate in the SiSU, act in a rational way, aiming their own interests in choosing the course in which they wish to join. The theory of rational choice, therefore, considers that the individual, endowed with rationality, makes his choices in order to achieve his own goal and have personal gains, based on the resources and information that he has. Following this reflection, it is believed that many of the individuals who enroll in the SiSU to try to apply for a place in the higher education system, make the choice of course based on what is possible to the detriment of what is desired. Therefore, this new system may be trivializing the choice of higher education. The suggestion that emerges is that efforts should be directed towards reflections and studies on the influence of SiSU on student behavior in the choice of course. In addition, the importance of considering the cultural and non-rational aspects of the individuals who subscribe to the SiSU is also suggested.

Keywords: Theory of Rational Choice. ENEM / SiSU. Choice of Superior Course.

\section{INTRODUÇÃO}

A todo tempo, seja nas organizações ou até mesmo na vida pessoal, os indivíduos têm de tomar decisões e fazer escolhas diante de situações ou problemas diversos. Essas decisões poderão representar tanto o sucesso como o fracasso das pessoas que estão à frente do processo decisório, das que dependem deste processo ou, até mesmo, de uma organização.

Este ensaio teórico se insere no campo das políticas públicas em educação visto que, discutirá, à luz da teoria da escolha racional, qual pode estar sendo a lógica da escolha do curso superior, por meio da seleção do Sistema de Seleção Unificada (SiSU), enquanto forma de acesso às Instituições de Ensino Superior (IES) brasileiras. Esse esforço será interessante ao refletir sobre este enfoque racional, analisando

\footnotetext{
${ }^{1}$ Universidade Federal de Viçosa
} 
o que leva o estudante a escolher um determinado curso superior, pois acredita-se que esse olhar sociológico é uma ferramenta eficaz para a análise das escolhas individuais que se manifesta de forma clara no modo como o estudante escolhe qual o curso pretende seguir. Trazer à tona este debate pode ser de grande valia, pois por ser o SiSU uma política pública recente de acesso ao ensino superior, essa questão ainda é nova e pouco abordada.

Neste sentido, tem-se como proposição da política do SiSU que, os candidatos ao ingresso ao ensino superior que participam do processo seletivo por meio do SiSU, agem de modo racional, visando os seus próprios interesses ao escolher o curso que desejam ingressar. Infere-se que, nesse processo de escolha, os estudantes utilizam, principalmente, dos dados apresentados por este sistema de seleção e de informações externas sobre mercado de trabalho, rentabilidade, dentre outras, para tomar uma decisão mais estratégica. Para refletir sobre essa questão utilizar-se-á, portanto, das premissas da teoria da escolha racional.

A teoria da escolha racional emerge nos anos de 1980 e é definida como a teoria sociológica que se propõe a explicar o comportamento social e político considerando a ação individual como o principal ponto para a compreensão dos sistemas sociais, assumindo que as pessoas agem racionalmente. A principal posição dessa teoria refere-se ao fato de que os atores têm objetivos e preferências com diversos graus de intensidade e fazem escolhas para alcançar o seu próprio objetivo e ter ganhos pessoais. Portanto, a racionalidade é vista como um meio para atingir e maximizar essas preferências dos agentes dotados de cálculo utilitarista (BAERT, 1997; CAMPOS; BORSANI; AZEVEDO, 2016).

Acredita-se que, o mercado de trabalho, cada vez mais, vem se mostrando mais exigente e, consequentemente, a busca pelo ensino superior, como forma de aperfeiçoamento para a concorrência do mercado, é cada vez maior. Para tanto, elevou-se o número de candidatos que se encontram na condição de escolher o curso superior que pretende ingressar. Que esse processo de escolha é importante, todos hão de concordar, mas muitos se esquecem de analisar as influências, possibilidades e limitações destas escolhas e, até que ponto há liberdade e racionalidade na decisão tomada após a adesão das IFES ao ENEM/SiSU.

O Exame Nacional do Ensino Médio (ENEM) foi instituído no Brasil, em 1998, como uma forma de avaliar o nível de aprendizagem dos estudantes do ensino médio. Este processo foi amadurecido até que, em 2009, uma reformulação instituiu o Novo ENEM. Este novo exame tem por objetivo unificar o acesso ao ensino superior por meio das competências e habilidades que avalia, buscando estimular a compreensão e a relação da prática com os conhecimentos adquiridos em salas de aula.

Também no ano de 2009, criou-se, por meio do Ministério da Educação (MEC), o Sistema de Seleção Unificada (SiSU), um sistema informatizado, que só foi instituído no ano de 2010, com o objetivo de selecionar estudantes para as vagas de graduação das instituições públicas que dele participarem, utilizando somente as notas do novo ENEM (BRASIL, 2012). Hoje, com ampla adesão das IFES, o SiSU constitui-se como a principal forma de acesso ao ensino superior, sendo a escolha do curso inclusa em um novo cenário de um sistema totalmente on line.

A inscrição no SiSU, inicia-se quando o estudante vincula sua nota no ENEM ao sistema e especifica, em ordem de preferência, duas opções de vaga com curso, local de oferta, turno e modalidade de concorrência. Durante todo o período de inscrição, o SiSU disponibiliza em caráter exclusivamente informativo, a simulação da nota de corte por curso e modalidade de concorrência, a qual será atualizada diariamente. Dessa forma, o sistema possibilita que o estudante se inscreva em duas opções de cursos e/ou instituições de ensino diferentes. Assim, ao longo do processo de inscrição, o estudante poderá analisar as notas de corte, atualizar os dados informados no processo de inscrição, bem como modificar a escolha das opções dos cursos, sendo considerada, para fins de classificação, a última escolha confirmada na 
plataforma (BRASIL, 2012).

Dessa forma, de acordo com a dinâmica de funcionamento do SiSU, o estudante, ao fazer sua escolha quanto ao curso superior, já tem ciência da sua nota no ENEM e possui as informações, durante todo o período de inscrição do sistema, das simulações das notas de corte das suas opções de escolha e de todos os outros cursos, além da sua posição no ranking de classificação junto aos demais concorrentes. Assim, o candidato já se tem ciência sobre qual a probabilidade de ser classificado para uma determinada vaga, podendo tomar a decisão de se manter na vaga escolhida ou buscar uma outra em que sai nota no Exame seja suficiente para aumentar as chances de ingresso no ensino superior.

Por fim, este trabalho tem por objetivo discutir, à luz da teoria da escolha racional, qual seria a lógica da escolha do estudante por um curso superior após a adesão do ENEM/SiSU nas Instituições de Ensino Superior brasileiras. Apresenta-se como proposição, que os candidatos que participam do SiSU, agem de modo racional, visando os seus próprios interesses na escolha do curso no qual desejam ingressar. O presente ensaio teórico será divido, além desta introdução, em mais quatro seções. Na primeira, será discorrido sobre a teoria da escolha racional, seus conceitos e usos. A segunda seção trata-se da revolução do ENEM/SiSU e da dinâmica de funcionamento deste sistema, onde é realizado o processo de escolha e seleção do curso superior. Na quarta seção, tem-se a reflexão, à luz da teoria da escolha racional, sobre a escolha do curso de nível superior por meio do processo seletivo do SiSU. Por último, são apresentadas as considerações finais a respeito desta reflexão.

\section{A TEORIA DA ESCOLHA RACIONAL}

A Teoria da Escolha Racional (BAERT, 1997; BODART, 2016) se apresenta como uma forma de buscar compreender as relações sociais e o comportamento humano dentro das organizações, principalmente no processo de escolha, tomada de decisão e resolução de problemas. Essa teoria emergiu nos anos de 1980 e é definida como a teoria sociológica que se propõe a explicar o comportamento social e político assumindo que as pessoas agem racionalmente, o que leva a um conjunto de ações e consequências visando atingir seus próprios interesses ou preferências. Tal teoria traz a imersão do homem econômico ${ }^{2}$ como um ator que predomina em relação ao homem social ${ }^{3}$. Nessa época, a importância da racionalidade do homem econômico já havia sido enfatizada por outros pensadores como, por exemplo, Hobbes e Adam Smith (BAERT, 1997).

Esta abordagem teórica considera a ação individual, a partir de motivações racionais, como o principal ponto para a compreensão dos sistemas sociais, considerando as instituições como os elementos informativos das opções disponíveis para escolhas. A principal posição da teoria da escolha racional refere-se ao fato de que os atores têm objetivos e preferências com diversos graus de intensidade e fazem escolhas para alcançar o seu próprio objetivo. Portanto, a racionalidade é vista como um meio para atingir e maximizar essas preferências dos agentes dotados de cálculo utilitarista. Assim, de acordo com essa teoria, o indivíduo é capaz de prever e calcular os valores e utilidades esperadas a partir das consequências de suas escolhas. Uma escolha, portanto, implica o abandono de uma ou mais opções, em nome de uma opção hierarquicamente preferida. Deste modo, haverá custos nessas decisões (CAMPOS; BORSANI; AZEVEDO, 2016).

\footnotetext{
${ }^{2}$ Preocupa-se somente com o dinheiro, ou seja, só se motiva financeiramente. É analisado apenas no que tange à racionalidade econômica.

${ }^{3}$ De acordo com esse conceito, o homem tem outras necessidades motivacionais que estão acima das motivações salariais e outros benefícios financeiros. Aqui, o homem é visto como um ser que necessita de interação com outras pessoas da organização para compartilhar valores e sentimentos.
} 
De modo geral, a ação individual, na maioria das vezes, consiste em uma ação que visa atingir objetivos do próprio agente. De acordo com Bodart (2016), a teoria da escolha racional refuta a ideia de ação coletiva como unidade de análise, pois são os indivíduos que agem, ou seja, são essas ações individuais que vão compor o coletivo. Estes, por sua vez, sendo racionais, buscam a otimização de seus ganhos, visando o seu próprio bem-estar. Essa teoria, portanto, de acordo com o autor, tem como premissa o individualismo, a otimização e o egocentrismo ${ }^{\mathrm{i}}$.

De acordo com Ferejohn e Pasquino (2001), o conceito de ação racional, alicerce para a teoria da escolha racional, seria um ato escolhido pelo agente que, de acordo com suas preferências, crenças e desejos, seria a melhor opção possível. São esses desejos e crenças, definidos antes da ação, que serão satisfeitos na escolha. Portanto, o processo de escolha que será racional, mas são as crenças e desejos do indivíduo que indicam a "melhor escolha" para si.

A racionalidade não exige das pessoas a certeza do que querem, nem que tenham o conhecimento de todas as opções disponíveis, que sejam perfeitamente informadas e que saibam exatamente o que fazer com tais informações, pois ela se ampara nos recursos e informações disponíveis aos atores. Até mesmo porque essas informações disponíveis são escassas e possuem custos (CAMPOS; BORSANI; AZEVEDO, 2016). De acordo com Baert (1997), o indivíduo racional é capaz de, dentro do possível e de forma equilibrada, reunir informações que dê embasamento para suas convicções. Diz-se de forma equilibrada, pois, ao contrário, o excesso de informações pode ser sinal de irracionalidade, isso porque, conforme Amaral e Sousa (2011), o excesso de informação dificulta encontrar a informação realmente relevante.

Nesse contexto, essa teoria mostra como as decisões são relativas e como o ser humano possui limites no processo decisório, destacando o próprio acesso às informações que geram a "assimetria da informação". Além disso, dependendo da posição hierárquica social ou dos lugares que os indivíduos frequentam, da tecnologia à qual se tem acesso e das fontes de informação, os dados nos quais os indivíduos vão basear as decisões pode variar. É a racionalidade limitada que mostrará esses limites, pois além de tudo isso, o indivíduo possui também limitações no processamento de todos esses dados. Portanto, o processo decisório se faz pela primeira opção que mais the parece satisfatória, de acordo com os recursos que possuir no momento. A teoria da escolha racional, portanto, considera os interesses dos agentes não de forma isolada, mas como indivíduos que integram livremente uma estruturação social.

Desta forma, a teoria da escolha racional considera que os indivíduos possuem a capacidade de fazer associações entre os meios, disponíveis e conhecidos, e os fins que almejam, sendo que a distância entre preferências e benefícios interferirá no tipo de escolha. No entanto, a utilização da racionalidade nem sempre fará com que os resultados esperados sejam ótimos e maximizadores da utilidade ou do bem-estar, pois, pode ocorrer que ações racionais apresentem efeitos negativos não esperados em função das assimetrias informacionais, da posição no espectro decisório e/ou de erros de cálculo (CAMPOS; BORSANI; AZEVEDO, 2016).

No entanto, uma crítica que se faz a teoria da escolha racional é a de que ela propõe que, diante das mesmas situações e assumindo as preferências constantes, existe único "modo racional de agir", livre de qualquer especificação cultural. Ou seja, a noção de racionalidade que os teóricos da escolha racional se apoiam não levam em conta que o contexto cultural no qual as pessoas se encontram afetam o que elas consideram ser ou não uma convicção fundada na razão (BAERT, 1997).

Portanto, vale refletir sobre os usos da teoria da escolha racional. Essa abordagem teórica é empregada de forma sofisticada para compreender diversos aspectos da vida social. Esse olhar sociológico, advindo da economia, sobre as escolhas individuais é uma questão bem presente nas pesquisas da ciência política, da ciência social, da economia e da teoria das organizações. Diversos trabalhos utilizam essa teoria para tentar compreender comportamentos que se relacionam com os mais 
diversos assuntos, como por exemplo, religião, criminologia, política, organizações, dentre outros, como se pode verificar no parágrafo seguinte.

Baert (1997) traz exemplos das aplicações da teoria da escolha racional em diferentes momentos. De acordo com o autor, um dos primeiros livros da teoria que explora as aplicações da Ciência Política foi An economic theory of democracy (1957), de Anthony Downs. Mancur Olson de Jr. (1965) escreveu o livro The logic of collective action, tentando utilizar a mesma perspectiva para compreender as organizações, ou seja, o que Downs conseguiu fazer na ciência política, Olson fez na teoria das organizações. Este autor trabalhou com as organizações que tratam dos interesses comuns de seus membros, dando foco aos "bens públicos", que são aqueles que, uma vez alcançados, não podem ser tirados dos demais membros de um determinado grupo. Em Economic approach to human behavior, Gary Becker (1976) agrupou artigos que tentavam demonstrar a ampla aplicabilidade do enfoque econômico a uma grande variedade de fenômenos, abrangendo desde consumo de drogas até casamentos. Em 1990, James Coleman escreve o livro Foundations of social theory como uma contribuição à teoria social a partir de uma perspectiva da teoria da escolha racional.

O trabalho de Bodart (2016) discutiu, à luz da teoria da escolha racional, da teoria dos jogos e do conceito de capital social, quais são as motivações para a ação coletiva da população em parceria com o poder público local, tomando como estudo de caso uma ação coletiva ocorrida em 2011 no município de Piúma, localizado no sul do estado do Espírito Santo. A incredibilidade nos políticos locais, o individualismo e a racionalidade foram fatores-chaves para a ação. No caso em estudo, a racionalidade dos indivíduos levou-os a buscar um ganho subótimo, uma vez que a solução ótima seria o poder público, tão somente, prover a pavimentação de uma rua, o que não foi possível. Quanto aos esforços para se apropriar da teoria dos jogos e da teoria da escolha racional, identificou-se neste trabalho que, tais teorias podem ser mobilizadas a fim de compreender melhor a realidade social.

Depois de discorrido sobre a teoria da escolha racional, suas proposições e conceitos, será apresentado, a seguir, a revolução que a política pública do ENEM/SiSU trouxe para o acesso ao ensino superior no Brasil, como esse sistema funciona e como ele pode impactar na escolha do candidato quanto ao curso superior.

\section{ENEM/SISU: A ESCOLHA DO CURSO SUPERIOR}

Durante muito tempo, a única forma de selecionar os estudantes para o acesso ao ensino superior no Brasil, era por meio do tradicional vestibular. Entretanto, no decorrer dos anos, várias foram às críticas a respeito desta forma de seleção, pois se acreditava que essa forma de selecionar os estudantes dava ênfase a simples memorização. Além da questão da memorização, a argumentação utilizada era a de que, apesar de o vestibular conseguir conduzir o processo de seleção com base na qualidade, aquele cria dificuldades de acesso aos candidatos que não podem se deslocar até cada instituição que deseja concorrer por questões econômico-financeiras. A partir disso, no ano de 2009, o MEC enviou uma proposta de reformulação do ENEM à Associação Nacional dos Dirigentes das Instituições Federais de Ensino Superior (ANDIFES), trazendo em seu cerne a unificação da seleção das vagas das IFES por meio de uma única prova, o novo ENEM.

Ademais, a nova prova traria a possibilidade concreta do estabelecimento de uma relação positiva entre ensino médio e ensino superior, repensando as diretrizes e discutindo a relação entre conteúdos exigidos para o ingresso na educação superior e habilidades que seriam fundamentais, tanto para o desempenho acadêmico futuro, quanto para a formação humana (BRASIL, 2009). 
Viu-se no ENEM a possibilidade de unificar o processo de seleção ao ensino superior, pois algumas mudanças neste sentido já começaram a ser feitas alguns anos após a criação deste exame em 1998, quando este tinha por objetivo avaliar os estudantes egressos do nível médio de ensino. As mudanças começaram então, quando algumas instituições, em sua maioria privadas, passaram a utilizá-lo como primeira fase de seu processo seletivo. No ano de 2001, o governo isentou o pagamento da taxa de inscrição dos concluintes do ensino médio de escolas públicas, visando democratizar o acesso de todos ao exame. Em 2003 foi incluído o questionário socioeconômico para os inscritos, como forma de ajudar na compreensão de seus desempenhos. Já em 2004, o ENEM passou a ser empregado como instrumento de seleção para os alunos concorrentes a bolsas para o ingresso em instituições de ensino superior privadas, o que caracterizou o Programa Universidade para Todos (PROUNI), o que deu uma maior visibilidade ao ENEM. A última alteração significativa ocorreu no ano de 2005, quando se iniciou a divulgação das notas médias das escolas, além das notas individuais dos estudantes de cada escola que já eram divulgadas, com o propósito de avaliar o desempenho das instituições (SAMPAIO, 2012; SANTOS, 2011).

A principal diferença do novo ENEM em relação ao antigo modelo é que, até então, a prova era composta por 63 (sessenta e três) itens interdisciplinares, com menor ligação com os conteúdos ministrados no ensino médio e sem a possibilidade de comparação das notas dos alunos de um ano para outro. O novo ENEM permitiu a comparação de desempenho dos candidatos em um período de tempo, possibilitando assim, a organização de dados históricos de grande valor educacional. O novo exame passou a ser composto por perguntas objetivas, as quais são divididas em quatro áreas do conhecimento: linguagens, códigos e suas tecnologias; ciências humanas e suas tecnologias; ciências da natureza e suas tecnologias; e matemáticas e suas tecnologias. Cada área é composta por 45 (quarenta e cinco) questões de múltipla escolha, sendo que no primeiro dia de prova são realizadas as questões de duas áreas do conhecimento e no segundo dia as outras duas áreas restantes mais a redação (ANDRIOLA, 2011).

A partir disso, tornou-se necessário a criação de um sistema que gerenciasse as notas no exame e, consequentemente, as vagas no ensino superior. Assim, também no ano de 2009, o MEC criou a política pública de acesso ao ensino superior do Sistema de Seleção Unificada (SiSU), um sistema informatizado para selecionar estudantes para as vagas de graduação das instituições públicas que dele participarem, utilizando somente as notas do novo ENEM (BRASIL, 2012). Com isso, o ENEM passou a ser usado como processo seletivo para a inserção de estudantes ao ensino superior, substituindo, gradualmente, o tradicional vestibular.

De acordo com Secchi (2013, p.1) "Uma política pública é uma diretriz elaborada para enfrentar um problema público". Ou seja, a política pública é um conjunto de ações a partir de uma orientação com vistas a solucionar um problema tido como relevante pela coletividade. É a intenção de se resolver um problema público que vai definir se a política é ou não pública (SECCHI, 2013). Portanto, a política de acesso ao ensino superior do SiSU é uma política dirigida ao enfrentamento de um problema público: a necessidade de democratização do acesso ao ensino superior dos brasileiros.

A inscrição no SiSU funciona da seguinte forma: o estudante vincula sua nota no ENEM e especifica, em ordem de preferência, suas opções de vaga em instituição, local de oferta, curso, turno e modalidade de concorrência ii . A partir do segundo até o último dia de inscrição, o SiSU disponibilizará, em caráter exclusivamente informativo, a simulação da nota de corte por curso e modalidade de concorrência (a nota do último classificado), a qual será atualizada diariamente até o final do período de inscrição. Dessa forma, o estudante poderá escolher sua primeira e segunda opção para se inscrever e alterá-las durante esse período, sendo considerada, para fins de classificação, a última escolha efetuada e confirmada no sistema. Após o processo de matrícula dos estudantes aprovados na chamada regular, as vagas não preenchidas são ofertadas para estudantes que constarem na lista de espera. Nesta etapa, alunos 
que ainda tiverem interesse na vaga deve se manifestar por meio do sistema para participar da lista de espera (BRASIL, 2012).

No entanto, como o último dia é decisivo, novos problemas vêm surgindo, como congestão do sistema já que um grande número de universidades federais adota o SiSU como o único mecanismo de ingresso. Por isso, o provável congestionamento do último dia pode levar a sobrecarga dos servidores e fazer com que algumas inscrições não sejam realizadas (ITABORAI, 2013).

Assim, o estudante que antes, com o vestibular, precisaria realizar as provas de seleção próprias de cada instituição, hoje, com a prova do ENEM de caráter nacional e com o SiSU totalmente on line, ele pode realizar uma única prova na sua cidade/estado de origem e concorrer a vagas de todo o território nacional. Com isso, acredita-se que um maior número de estudantes poderá concorrer às vagas das IFES no Brasil, incorrendo em menores gastos financeiros, haja vista que o estudante não precisa mais dispender gastos com deslocamento para a realização das provas e nem com um maior número de inscrições para ampliar as oportunidades de ingresso. Por tudo isso, acredita-se que o SiSU amplia o olhar do estudante para as oportunidades de vagas e instituições de todo o território nacional, ou seja, propicia maior conhecimento, e consequentemente, maior acesso das opções existentes no país.

Quando o estudante se inscreve na plataforma do SiSU, ele já tem informações sobre sua nota no ENEM, pode escolher até duas opções de curso, além de possuir análises diárias da sua posição frente aos concorrentes. Por conta disso, acredita-se que com o SiSU, torna-se mais fácil ponderar as preferências do estudante com sua real capacidade de ingresso em um curso superior, dado que o grau de informação obtida no sistema aumenta (RAMOS, 2017). Entretanto, sabe-se que essa dinâmica pode estar gerando efeitos negativos na escolha do curso. Quanto à escolha do curso superior por meio da plataforma do SiSU, Melo (2017, p.83) afirma que "o modelo de ingresso no ensino superior e o de formação profissional utilizado atualmente no Brasil, não tem privilegiado a tomada de decisão baseada no processo de autoconhecimento necessário para uma decisão assertiva". Portanto, o autor acredita que o novo sistema de ingresso exerce influência sobre a escolha do curso dos candidatos, baseado no curso possível de ingresso, em detrimento do desejado, o que pode estar interferindo na permanência do estudante no ensino superior.

Compreendido o funcionamento e os objetivos pretendidos com a implementação do ENEM/SiSU, na próxima seção, será discutido, à luz da teoria da escolha racional, a escolha do curso superior por meio do ambiente do SiSU.

\section{COMPREENDENDO A ESCOLHA NO SISU PELA TEORIA DA ESCOLHA RACIONAL}

Objetiva-se aqui tratar da teoria da escolha racional sem perder de vista o tema central: o comportamento do estudante na escolha do curso superior por meio do processo de seleção do SiSU. Acredita-se que esse olhar sociológico sobre as escolhas individuais ajuda a compreender, de forma clara, o modo como o estudante escolhe qual o curso pretende seguir.

De acordo com a teoria da escolha racional, as ações dos agentes são racionais. Por isso, quando um estudante tem de escolher qual o curso superior que irá concorrer, deve-se ter coerência entre a tomada de decisão e o objetivo que o indivíduo deseja alcançar com essa escolha. No entanto, esse objetivo é relativo entre os estudantes. Aqui se tem dois importantes momentos, sendo um deles a descoberta de quais objetivos aquele que toma decisão está perseguindo e, o outro, a análise de quais meios são mais razoáveis para atingi-los. O candidato ao ingresso ao ensino superior pode, em sua hierarquia de preferências, visar, principalmente, o simples ingresso no sistema superior de ensino, em busca de um diploma, sem priorizar um curso em específico, tendo um leque maior de possibilidades de cursos. Ou 
então, o estudante pode visar o ingresso em um curso específico sem ter um grau elevado de preferência por uma instituição específica, ou vice-versa. É no segundo momento, ou seja, na análise dos meios para atingir seus objetivos, que a racionalidade mais vai se enquadrar.

Nesse contexto, a ação individual de o estudante decidir qual o curso superior ingressar é influenciada pelas informações que este agente obtém no momento. Ao escolher a carreira profissional, por exemplo, o candidato pode considerar as informações que possuem sobre mercado de trabalho, empregabilidade, salários, condições de carreira, dentre outros fatores. Sabe-se que essas informações serão relativas de candidato a candidato, ou seja, isso se relaciona com a questão da "assimetria de informação".

Uma vez que o SiSU se tornou a forma mais comum de ingresso do estudante ao ensino superior no Brasil, deve-se considerar o cenário de incertezas que compreende este sistema e sua forma de funcionamento, a fim de analisar as possíveis influências na escolha do estudante quanto ao curso que pretende ingressar. Por meio do SiSU, o candidato já sabe do seu desempenho no ENEM e possui as informações da simulação das notas de corte dos cursos e da sua posição no ranking de classificação junto aos demais concorrentes. Desse modo, o estudante tem condições de analisar melhor sua capacidade de conseguir ingressar em determinados cursos e/ou Instituições, pois se o candidato acreditar que não será possível o ingresso no curso que realmente deseja, o sistema pode lhe induzir à troca, o que evidencia a forte tendência de inserção do estudante em um curso que pode não ser sua principal preferência. Anteriormente, por meio do vestibular, o estudante só possuía as informações sobre a concorrência de anos passados e a escolha do curso era tomada antes da realização da prova.

Entende-se que, por meio do SiSU, o estudante estará sujeito a possibilidade de incoerências na escolha do curso se optar por uma profissão na qual não tem um real interesse, mas que possui maiores chances de ingresso por meio do SiSU. Isso tudo pode gerar aumento no número de estudantes evadidos e pode acabar comprometendo a entrada de novos alunos nas IFES brasileiras. Uma escolha equivocada quanto ao curso desejado pode ocasionar na não matrícula após a aprovação, ou até mesmo na evasão após o ingresso na Instituição de Ensino Superior. No entanto, vale ressaltar que pode haver consequências não previstas, haja vista que o SiSU faz apenas simulações, o que não garante que o cenário não poderá mudar ao final (NOGUEIRA et al., 2017; BRASIL, 2012).

A vontade, necessidade ou pressão urgente de adentrar ao ensino superior pode levar o estudante a calcular todas as possibilidades e, posteriormente, a tomar uma decisão estratégica. Escolher um curso de segunda opção (ou até uma segunda opção de instituição) relaciona-se com a forma de "satisfazer", ou seja, escolher algo que seja suficientemente bom, mesmo não sendo a escolha ótima. Os teóricos da escolha racional afirmam que os indivíduos tendem a maximizar seus benefícios, mas, quando não é possível alcançar uma situação ótima, ao menos buscam uma situação boa.

A teoria da escolha racional parte do pressuposto básico que os indivíduos, observam todas as suas oportunidades e agem de maneira estratégica para satisfazer o seu próprio interesse. Para isso, as escolhas dos indivíduos são baseadas em seu perfil socioeconômico e outras variáveis que poderão impactar não só na escolha do curso, mas também na escolha da instituição, do turno, dentre outras. Um estudante menos favorecido financeiramente, por exemplo, pode ser mais atraído pelo curso em período noturno, devido à necessidade de inserção no mercado de trabalho.

No entanto, como o SiSU simula informações sobre as notas de corte durante todo o processo de inscrição. Por tal motivo, há a possibilidade do estudante, em busca de um maior número de informações para basear sua decisão, demorar a escolher o curso e deixar a decisão para o último dia. Entretanto, isso pode trazer problemas ao candidato devido ao congestionamento do sistema no último dia de inscrição, o que pode acarretar na não inscrição do estudante, fato esse que é colocado como cláusula do edital de 
seleção do Sisu, visto a frequência de ocorrência deste problema.

\section{CONSIDERAÇÕES FINAIS}

Este ensaio teórico buscou discutir, à luz da teoria da escolha racional, qual poderia ser a lógica da escolha do estudante por um curso superior após a adesão do ENEM/SiSU nas Instituições Federais de Ensino Superior brasileiras. Apresenta-se como proposição, que os candidatos ao ingresso ao ensino superior, que participam do processo seletivo por meio do SiSU, agem de modo racional, visando os seus próprios interesses na escolha do curso no qual desejam ingressar.

A teoria da escolha racional, portanto, considera que o indivíduo, dotado de racionalidade, faz suas escolhas de modo a alcançar o seu próprio objetivo e ter ganhos pessoais, com base nos recursos e informações que dispõe. Neste sentido, essa teoria foi importante para compreender a escolha do curso superior no ambiente do SiSU, embora essa teoria apresente algumas limitações explicativas, como o fato de não possibilitar entender as influências culturais e não racionais, como por exemplo, os sentimentos que levam os indivíduos a certas escolhas.

Decorrendo desta reflexão, acredita-se que muitos dos indivíduos que se inscrevem no SiSU para tentar pleitear uma vaga no sistema superior de ensino, fazem a escolha do curso baseado no que é possível em detrimento do que é seu principal interesse. Portanto, esse novo sistema pode estar banalizando a escolha do curso superior. Sabe-se que esse fato pode levar tanto os estudantes a evadirem quanto a traçarem estratégias para corrigir essa escolha por meio das transferências de curso ou até mesmo do reingresso por meio de uma nova candidatura ao SiSU.

A sugestão que emerge é que, sejam direcionados esforços para reflexões e estudos sobre a influência do SiSU no comportamento do estudante ao escolher o curso que pretende ingressar. Ressaltase que por ser o SiSU uma política pública de acesso ao ensino superior ainda muito recente, poucas são as pesquisas com relação a essa política de acesso ao ensino superior, principalmente com esse enfoque teórico. Além disso, sugere-se também a importância em se considerar os aspectos culturais e não racionais dos indivíduos que se inscrevem no SiSU.

\section{REFERÊNCIAS}

AMARAL, S.A. do; SOUSA, A.J.F. P.de. Qualidade da informação e intuição na tomada de decisão organizacional. Perspectivas em Ciências da informação, v. 16, n. 1, p. 133-146, jan/mar. 2011.

ANDRIOLA; W.B. Doze motivos favoráveis à adoção do Exame Nacional do Ensino Médio (ENEM) pelas Instituições Federais de Ensino Superior (IFES). Ensaio: aval. pol. públ. Educ., Rio de Janeiro, v. 19, n. 70, p. 107-126, jan./mar. 2011.

BAERT, P. Algumas limitações das explicações da escolha racional na Ciência Política e na Sociologia. Revista Brasileira de Ciências Sociais, v. 12, n. 35, 1997.

BODART, C.das N. Contribuições da Teoria dos Jogos, da Escolha Racional e do conceito de Capital Social para o estudo da cooperação entre sociedade e poder público local. Sociais e Humanas, Santa Maria, v. 29, n. 03, p. 26 - 4, set/dez 2016.

BRASIL. Ministério da Educação. Portaria Normativa N 21, de 5 de Novembro de 2012. 2012.

BRASIL. Ministério da Educação. Proposta apresentada à Associação Nacional dos Dirigentes das Instituições Federais de Ensino Superior (Andifes). 2009. 
CAMPOS, M.M.; BORSANI, H.; AZEVEDO, N.L.de. Méritos e limites da teoria da escolha racional como ferramenta de interpretação do comportamento social e político. Ciências Sociais Unisinos, v. 52, n. $1,2016$.

FEREJOHN, J.; PASQUINO, P. A teoria da escolha racional na ciência política: conceitos de racionalidade em teoria política. Red Revista Brasileira de Ciências Sociais, 2000.

ITABORAI, F. L. S. Matching Theory e o acesso dos estudantes às instituições de ensino, com uma aplicação ao novo sistema SISU no Brasil. Monografia (Especialização em Ciências Econômicas). 44f. Faculdade de Economia, Administração e Contabilidade, Universidade de Brasília - UnB, Brasília, 2013.

MELO, K. C. Escolha de curso e evasão universitária: análises a partir do Sistema de Seleção Unificada. 2017. 98 f. Dissertação (Mestrado em Gestão de Pessoas Institucionais) - Universidade Federal do Rio Grande do Norte, Natal, 2017.

NOGUEIRA, C. M. M. et al. Promessas e limites: o SiSU e sua implementação na Universidade Federal de Minas Gerais. Educação em Revista, v. 33, 2017.

RAMOS, A.de A. O efeito do SiSU sobre a evasão e mudança de curso no ensino superior brasileiro. Monografia (Especialização em Ciências Econômicas). 35 f. Universidade de Brasília - UnB, Brasília, 2017.

SAMPAIO, E.M.R. O exame nacional do ensino médio (enem) nas escolas de Campo Grande/MS: A influência na prática pedagógica segundo os professores de matemática. 158f. Dissertação (Mestrado em Educação). Universidade Católica Dom Bosco, Campo Grande, 2012

SANTOS, J.dos. Política Pública de Acesso ao Ensino Superior: Um Olhar Sobre a Utilização do ENEM/SISU na Universidade Federal do Recôncavo da Bahia. Anais: XI Congresso Luso Afro Brasileiro de Ciências Sociais. Ondina: UFBA, 2011.

SECCHI, L. Políticas públicas: conceitos, esquemas de análise, casos práticos. 2. ed. São Paulo: Cengage Learning, 2013.

\footnotetext{
${ }^{\mathrm{i}}$ Egocentrismo refere-se a um conjunto de atitudes ou comportamentos indicando que um indivíduo se refere essencialmente a si mesmo. Qualidade, condição ou caráter de egocêntrico; egoísmo.

${ }^{i i}$ No ato da inscrição no SiSU, o estudante deverá optar por uma das modalidades de concorrência, a saber: I - às vagas reservadas pela Lei de Cotas (Lei $\mathrm{n}^{\circ} 12.711$, de 2012), observada a regulamentação em vigor;

II - às vagas destinadas às demais políticas de ações afirmativas eventualmente adotadas pela instituição no Termo de Adesão ao SiSU;

III - às vagas destinadas à ampla concorrência.
} 